\title{
Concepções e relações estabelecidas entre planejamento e avaliação: o papel do coordenador pedagógico
}

\author{
Mônica da Silva Gallon ${ }^{1}$ \\ Zulma Elizabete de Freitas Madruga² \\ Carla Melo da Silva ${ }^{3}$
}

João Bernardes da Rocha Filho ${ }^{4}$

\section{Resumo}

O artigo apresenta uma análise das concepções e relações que professores integrantes de uma escola localizada na região metropolitana de Porto Alegre, RS, mantêm sobre planejamento e avaliação. As ideias desses docentes são investigadas a partir do foco no papel do coordenador pedagógico e de como este influencia o espaço escolar. O estudo foi de caráter qualitativo e, para o tratamento dos dados, empregou-se a Análise Textual Discursiva. Como resultado, observou-se convergências quanto à forma de perceber a avaliação, não como produto final, mas como modo de redirecionar as práticas e repensar a atuação docente.

Palavras-chave: Coordenador Pedagógico; Planejamento; Avaliação.

Conceptions and relationships established between planning and evaluation: the role of the pedagogical coordinator

\section{Abstract}

The article presents an analysis of the conceptions and relationships that teachers who are part of a school, located of the metropolitan region of Porto Alegre, RS, think about planning and evaluation. The ideas of these teachers are investigated from the role of the pedagogical coordinator and how they can interfere in the school space. The study was qualitative and, for the treatment of the data, was used Discursive Textual Analysis. As a result, we observed convergences on how to perceive evaluation, not as a final product, but as a way of redirecting its practices and rethinking its teaching performance.

Keywords: Pedagogical Coordinators; Planning; Evaluation.

\section{Introdução}

Para o adequado cumprimento das diversas atribuições de um professor em seu exercício profissional é exigido um rol de atitudes, em acréscimo à simples disposição de executá-las. Como exemplo, é necessário que se tenha clareza nos propósitos das atividades, além de organização esmerada, necessárias para que tarefas com prioridades variadas sejam realizadas

\footnotetext{
${ }^{1}$ Pontifícia Universidade Católica do Rio Grande do Sul - PUCRS, Porto Alegre/RS, monica.gallon@gmail.com

2 Universidade Estadual de Santa Cruz - UESC, Ilhéus/BA, zefmadruga@uesc.br

${ }^{3}$ Pontifícia Universidade Católica do Rio Grande do Sul - PUCRS, Porto Alegre/RS, carlamelodasilva2015@gmail.com

${ }^{4}$ Pontifícia Universidade Católica do Rio Grande do Sul - PUCRS, Porto Alegre/RS, jbrfilho@pucrs.br
} 
em ordem coerente com suas prioridades. Os obstáculos a serem superados no cotidiano docente são muitos, porém o planejamento e a avaliação podem ajudar, e por isso são temas que constantemente permeiam o trabalho educativo, requerendo reflexão frequente, incluindo o conhecimento sobre como o sujeito professor percebe essas questões.

O coordenador pedagógico (CP) tem papel fundante nas demandas documentais e organizacionais da escola, bem como nas questões pedagógicas e na formação continuada do profissional em serviço. Trazer à discussão temas como o planejamento docente e o processo avaliativo é tarefa pertinente a esse profissional, assim como a orientação e o acompanhamento desses processos. Conforme Batista (2006, p.111):

A coordenação pode se configurar como prática social caracterizada pela mediação técnico-pedagógica na medida em que traduza consideração pelos sujeitos envolvidos e suas histórias; compromisso com um projeto educativo que esteja sintonizado com diálogos entre e com os diferentes; assunção do trabalho coletivo como uma importante estratégia de trabalho; investimento num processo de planejamento baseado na cooperação e na troca de saberes e experiências.

Além disso, de acordo com Miziara, Ribeiro e Bezerra (2014), é importante a presença do CP na convivência diária no ambiente escolar, mediando as tensões emergentes, o que exige deste sujeito estudo constante e competência para sistematizar de forma não autoritária o fazer docente. Esse convívio também deve ser fonte de diálogo e reconhecimento das práticas pedagógicas e saberes do grupo do qual faz parte. O olhar e a escuta sensível do $\mathrm{CP}$ devem agregar ao seu papel de formador a promoção de momentos que ampliem a reflexão filosófica dos professores sobre seus trabalhos e papéis sociais (MIZIARA; RIBEIRO; BEZERRA, 2014).

É imprescindível ao CP ter conhecimento sobre como os docentes da escola concebem determinadas questões a fim de auxiliá-los na tomada de decisões e orientá-los por meio da prática de formação continuada em serviço. Para Tardif (2014, p.21):

Se admitirmos que o saber dos professores não provém de uma fonte única, mas de várias fontes e de diferentes momentos da história de vida e da carreira profissional, essa própria diversidade levanta o problema da unificação e da recomposição dos saberes no e pelo trabalho.

Os saberes de cada professor, adquiridos de diferentes formas em suas trajetórias pessoais, acadêmicas e profissionais agregam conhecimento aos encontros formativos, 
cooperando nas construções coletivas. Sendo assim, momentos pedagógicos que propiciem o compartilhamento das experiências, expectativas ou pensamentos relacionados a uma temática mostram-se essenciais para um trabalho que envolva todos em uma atmosfera de ensinamentos e aprendizagens, transcorrendo de forma democrática e respeitosa.

Assim, o objetivo deste estudo foi analisar as concepções de um grupo de professores pertencentes a uma escola da região metropolitana de Porto Alegre, RS, referentes ao planejamento e avaliação escolar e a relação do CP frente a essas questões.

\section{Planejamento, avaliação e o coordenador pedagógico}

Para Fusari (1990, p.45, grifos nossos) o planejamento deve ser "concebido, assumido e vivenciado no cotidiano da prática social docente como um processo de reflexão". O ato de conceber demanda entender a real função do ato de planejar, tanto do momento dedicado, quanto à importância do material produzido e sua intencionalidade pedagógica. Assumir requer reconhecer aquilo que foi concebido, articulado à prática docente, aclarando teorias implícitas e explícitas nos fazeres e nos discursos. Vivenciar é atuar de forma natural do modo que foi explicitado, sem necessidade de esforços extras ou experimentos pontuais. É ser o seu eu docente. Já a reflexão é o elemento que norteia esse espiral construtivo, permitindo ao professor repensar seus fazeres de forma a redirecionar práticas que não atingiram o resultado esperado, bem como aquelas exitosas, mas que podem ser repensadas em outros contextos de maneira aprimorada e compartilhada.

Segundo Gandin (1991), o planejamento visa a eficiência (no fazer bem as coisas que se fazem), mas também a eficácia (sendo as coisas socialmente desejáveis). O autor salienta ainda a importância do planejamento nas ações humanas, e que este deve ser visto como um processo educativo (GANDIN, 1991). Fusari (1990) ressalta que muitos professores fazem cópias ou fotocópias de documentos de anos anteriores para atender aos cumprimentos burocráticos exigidos pela instituição, e que esta tarefa é incluída entre seus fazeres docentes obrigatórios, consumindo tempo e causando estresse, apesar de não refletir necessariamente suas construções e resultados educacionais alcançados.

A avaliação, portanto, está intimamente ligada ao planejamento, sendo consequência do

Periódico Horizontes - USF - Itatiba, SP - Brasil - e019048 
processo de conceber, assumir e refletir. Surge vinculada à prática educativa com o estudante, com o professor devendo diagnosticar a aprendizagem do conteúdo desenvolvido com determinado grupo, em dado período. Conforme Grillo e Lima:

Ao planejar sua aula, num processo proativo, o professor estabelece um julgamento sobre o conteúdo ser estudado e a forma de fazê-lo, sobre o aluno, sobre o tempo disponível, sobre os melhores procedimentos a partir de critérios de tempo, economia, adequação entre outros (2008, p.69).

Este segundo olhar sobre a avaliação também pode e deve ser discutido em conjunto com toda a equipe escolar com o objetivo de analisar e refinar suas formas de avaliar (GATTI, 2003). A avaliação confere ao professor e, por consequência, ao corpo docente, um momento para refletir sobre se os caminhos adotados para os processos de ensino e de aprendizagem em suas aulas foram os mais adequados, e de que formas pode-se pensar novos direcionamentos e adoção de metodologias ou ferramentas alternativas/adicionais. Pois, de acordo com Grillo e Lima (2008, p.70):

O professor aprende com as aprendizagens dos alunos: a forma como eles compreendem ou não as explicações, a lógica dos seus acertos ou erros, o que não ficou claro e o que é preciso melhorar ou reformular; os alunos aprendem com os resultados da avaliação: compreendendo seus erros, buscando acertos, assumindo-se como protagonistas da sua aprendizagem.

Dessa forma, torna-se possível, por meio do conhecimento sobre as dificuldades dos estudantes, o professor e os demais integrantes da equipe docente repensarem e reformularem suas atuações. O CP, nessa situação, pode assumir um papel de mediação entre teorias e práticas executadas pelo grupo.

Em pesquisa realizada por Miziara e colaboradores (MIZIARA; RIBEIRO; BEZERRA, 2014), cujas fontes de investigação foram teses e dissertações apresentadas no país entre os anos de 2010 e 2012, descobriu-se que em algumas regiões do Brasil pode-se assumir a denominação do cargo de CP como sendo de Supervisor Educacional (SE). Para esses autores, o SE deveria possuir como sua principal atribuição a formação junto ao grupo docente, porém, constata-se seu exercício essencialmente voltado às questões burocráticas da coordenação. Outras revelações do estudo são a ausência de planejamento conjuntamente com formação insuficiente para o exercício do cargo, excesso de trabalho sem objetivos específicos e falta de comprometimento 
com o fazer coletivo (MIZIARA; RIBEIRO; BEZERRA, 2014). Portanto, torna-se evidente que o indivíduo que atua como CP (ou SE) deve estar tecnicamente preparado para o enfrentamento das adversidades que envolvem as atividades na escola, além de consciente do seu papel para o bem-estar e o trabalho coletivo, objetivando optar por atitudes mais adequadas diante das demandas escolares.

Neste sentido, o CP assume papel importante não apenas preocupando-se com as exigências organizacionais da escola, mas voltando-se às questões pedagógicas, debruçando-se sobre o planejamento do seu trabalho, da instituição e do coletivo docente. O planejamento das atividades, apesar de sua importância, muitas vezes acaba não se efetivando devido às variadas demandas do cotidiano do ambiente escolar. Porém, este planejamento, tanto no que tange ao fazer individual do docente - percebendo e refletindo sobre os propósitos para cada atividade quanto naquilo que toca no coletivo escolar - deve antever as necessidades e decisões, as quais requerem reflexão e posicionamento.

\section{Procedimentos metodológicos}

Este estudo foi desenvolvido com professores pertencentes a uma escola municipal de Ensino Fundamental, localizada em um município da região metropolitana de Porto Alegre, RS. A instituição foi inaugurada em 18 de dezembro de 2014, sendo os professores formadores do atual quadro funcional da escola advindos de outras escolas municipais, contratados ou ingressantes do último concurso público realizado. Na ocasião do estudo (2015), a escola contava com 22 professores, com diferentes formações, atendendo um público de 10 ao 70 ano do Ensino Fundamental. O tempo de atuação docente destes profissionais também era variado, com indivíduos com mais de vinte anos de regência de classe ao lado de outros, cumprindo seus primeiros meses de docência.

A escolha dos indivíduos envolvidos nesta pesquisa ocorreu de forma aleatória, sendo encaminhado um questionário para o e-mail pessoal de cinco professores. Antes do encaminhamento do e-mail foi esclarecido a estes participantes que se tratava de uma pesquisa de caráter qualitativo e que as questões não pretendiam a identificação dos envolvidos. 0 questionário foi dividido em duas etapas: a primeira, abarcando dados referentes à 
caracterização do participante da pesquisa e sua formação, e a segunda, visando as suas concepções e aplicações das ideias referentes a avaliação e planejamento (Quadro 1).

Quadro 1 - Questões respondidas pelos participantes da pesquisa.

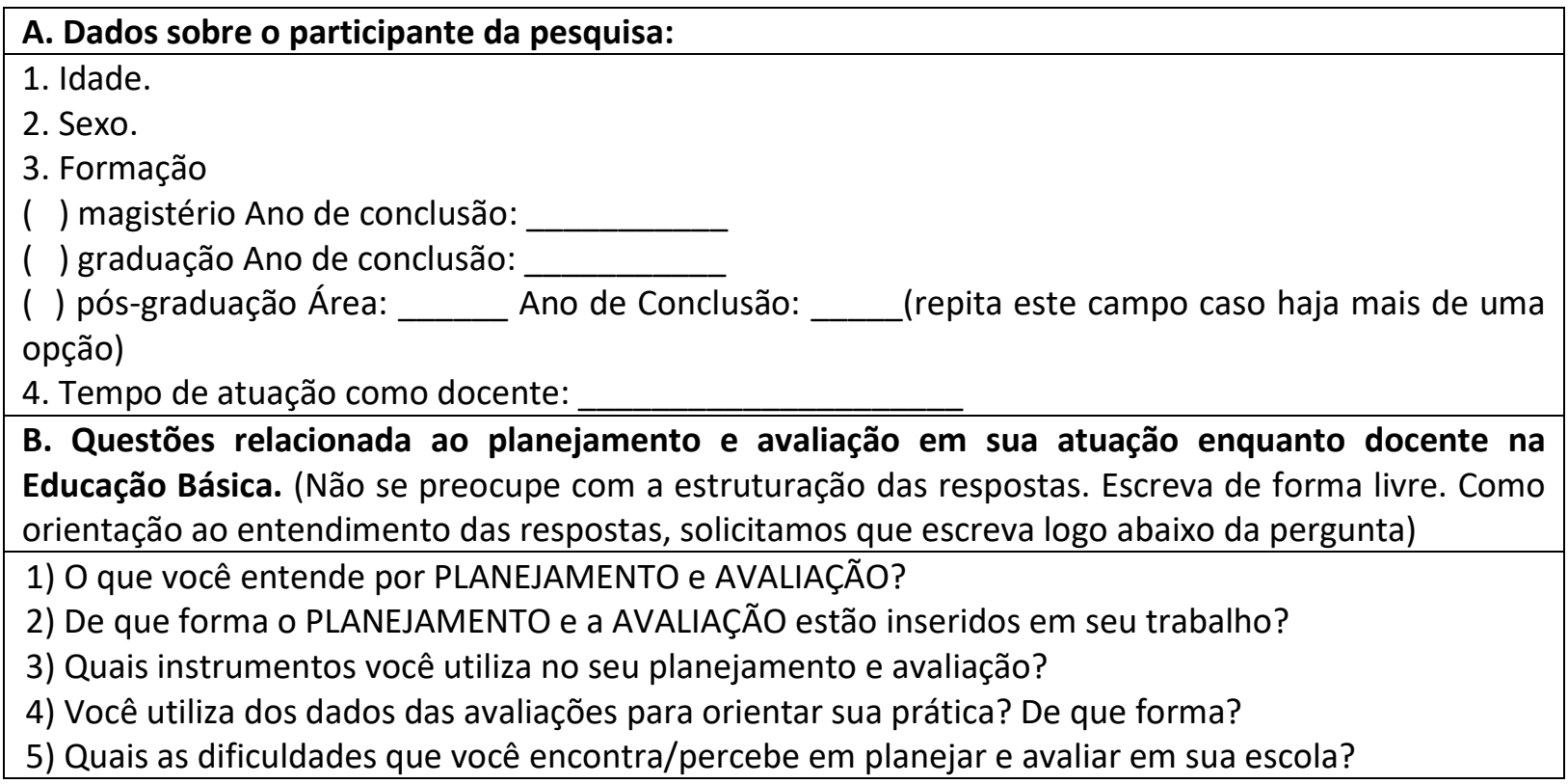
Fonte: Os autores (2018).

As respostas foram processadas por meio da Análise Textual Discursiva (ATD), descrita por Moraes e Galiazzi (2013). Com o uso dessa ferramenta analítica, o corpus de análise - no caso do presente estudo, constituído pelas respostas dos participantes ao questionário - é descontruído (unitarização) e as ideias apresentadas nos fragmentos passam a integrar as unidades de significado. Estas, por sua vez, são agrupadas de acordo com a similaridade dos seus sentidos, compondo um sistema de categorização, podendo ser reagrupadas, resultando em categorias finais. A criação das categorias pode ser realizada conforme as concepções do pesquisador, e podem ser do tipo a priori (quando especificadas antes do processo de unitarização), ou emergentes (quando criadas a partir dos conteúdos dos elementos unitarizados). Com base na etapa de categorização são organizados os metatextos, que descrevem e interpretam as ideias contidas nas categorias, trazendo à tona o novo emergente, juntamente com as teorias e concepções do pesquisador. Nesta pesquisa, assumiu-se o uso de categorias a priori.

Para Moraes e Galiazzi (2013, p.170), para uma ATD ser bem-sucedida é necessária "uma intensa impregnação com os materiais de análise. É importante que o pesquisador aproveite 
todas as oportunidades que se oferecem para se envolver intensamente com seu 'corpus' atingindo uma efetiva impregnação". Sendo assim, buscou-se a leitura e releitura das unidades encontradas e suas relações com as categorias estabelecidas, procurando-se a compreensão e a busca pelo novo emergente.

\section{Análise dos dados e discussões}

Obteve-se o retorno de três questionários, dos cinco distribuídos. A idade média dos participantes desta pesquisa, chamados aqui de A, B e C, foi de 34 anos, sendo todos pertencentes ao sexo feminino. Duas participantes apresentavam pós-graduação concluída e o tempo de docência do grupo variou de um mês a pouco mais de vinte anos. Optou-se por duas categorias de análise: "Concepções relacionadas ao planejamento e avaliação" e "Articulações entre planejamento, avaliação e atuação docente".

\section{Categoria 1: Concepções relacionadas a planejamento e avaliação}

Com relação às concepções das participantes sobre planejamento e avaliação, observouse que estas associam o planejamento à organização do trabalho. De acordo com a professora A: "planejamento entendo como um momento de organizar as atividades, planejando-as de acordo com as características do grupo de alunos que participarão das atividades". A professora C apresenta: "o planejamento é uma organização do trabalho, por meio da pesquisa e o pensar na ação pedagógica (conteúdos, atividades, tempo e avaliação)". Verifica-se uma convergência relacionada à organização do trabalho, mas modos diferentes de perceber como esta organização deve ser feita, ou seja, quanto a sua intencionalidade.

Este viés do planejamento faz parte da reflexão das docentes, que percebem em seus fazeres a necessidade de repensar sobre como isso deve estar imbricado no grupo com o qual está se desenvolvendo determinado trabalho. Também é preciso considerar o que Fusari (1990, p.46) sugere como uma confusão conceitual comum entre plano de ensino e planejamento, definindo plano de ensino como "um momento de documentação do processo educacional escolar como um todo, sendo um documento elaborado pelo professor contendo sua proposta

Periódico Horizontes - USF - Itatiba, SP - Brasil - e019048 
de trabalho abarcando objetivos, conteúdos, métodos e avaliação". Enquanto planejamento "envolve a atuação concreta dos educadores no cotidiano do seu trabalho pedagógico envolvendo todas as suas ações e situações, o tempo todo, envolvendo a permanente interação entre os educadores e entre os próprios educandos" (FUSARI, 1989, p.10).

Para a professora B "planejamento é o viés do trabalho, o alinhavo do que será posto em prática: um plano que iremos trabalhar". Entende-se que as concepções são variadas, e passíveis de serem modificadas ao longo da trajetória docente, pois estão diretamente relacionadas à reflexão cotidiana da prática e no quanto o planejamento pode guiar o trabalho do professor.

Relacionado à avaliação, observa-se a visão do professor quanto ao papel do estudante neste processo, como também a função da avaliação no trabalho do professor. Com vistas à dimensão do estudante, a professora C diz: "o processo de acompanhar a evolução da construção do conhecimento do educando se dá por meio da avaliação". Enquanto a professora A: "avaliação entendo como um acompanhamento do desempenho dos alunos. Esse desempenho não se restringe apenas a pontuações, mas principalmente trata de acompanhar o envolvimento e dedicação dos alunos". Para a professora B: "a avaliação é o resultado daquilo que o planejamento alicerçou". Conforme o depoimento da professora B, percebe-se a ideia de integração entre a avaliação e planejamento, assim como expresso por Campos (2010, p.52):

Como o planejamento de ensino e a avaliação são ações construídas no cotidiano, resultantes do diálogo entre a teoria e a prática e da interação com os alunos e seus saberes, ao professor cabe ajudá-los a refletir sobre o que já sabem e sobre como um conhecimento pode se relacionar a outro, devendo ser parte presente e constante dessa relação.

A autora acrescenta a noção do cruzamento entre a teoria e a prática, bem como a consideração aos saberes dos estudantes (CAMPOS, 2010), podendo então o professor construir um planejamento vivo, fazendo com que o aluno também participe desta ação.

Verifica-se nos depoimentos das três participantes da pesquisa maneiras diferentes de interpretar a avaliação, porém, o trio coloca a avaliação não apenas como algo que "categoriza" os estudantes, tal como a avaliação é vista muitas vezes, e sim como uma forma de medir o desempenho, porém no intuito de apontar caminhos na aprendizagem do estudante. A professora B vai além, ao dizer que a avaliação é produto do planejamento. Esta afirmação vai ao encontro do que afirma Campos (2010, p.54), quando expõe que o "planejamento pode 
potencializar diferentes formas de ensinar e aprender e que a avaliação deve trazer indicativos tanto para o professor quanto para os alunos".

Esta forma de ver a avaliação demonstra a responsabilidade do papel do professor em colocar em seu plano a sua intencionalidade, e de que modo pretende guiar sua avaliação, ao final do processo. Ainda com relação às ideias das participantes, observam-se suas impressões quanto à avaliação. Conforme a participante B: "a avaliação não é um fim... ela pode nortear e conduzir novos resultados e será feita tanto em relação ao sucesso do trabalho do professor quanto dos resultados obtidos pelos alunos". A docente deixa claro que a avaliação não deve ser o ponto final do processo de aprendizagem. Serve apenas como um registro tanto do trabalho do estudante quando da prática pedagógica do docente para atingir tal objetivo. Gatti (2003, p.102) recomenda que "a avaliação não seja apenas finalista, mas, sim, incluída no processo de ensino e aprendizagem como meio para o autodesenvolvimento, tanto dos alunos em suas aprendizagens, quanto dos professores, como profissionais, em face das suas formas de ensinar". Grillo e Lima (2010, p.17) afirmam:

\footnotetext{
Igualmente para o professor, a avaliação da aprendizagem é de reconhecida utilidade, na medida em que permite reflexão sobre a prática - o exame da coerência entre os objetivos buscados, os procedimentos de ensino utilizados e os resultados obtidos - e orienta a tomada de decisões pertinentes para a continuidade do ensino.
}

Percebe-se a avaliação como um elemento importante a todos os atores envolvidos: seja para o professor refletir sobre a eficácia de suas ações, seja para o estudante, para que perceba o que foi aprendido e o que precisa ser retomado, seja a instituição, para constatar em que medida as ações educativas que vêm sendo praticadas são condizentes com sua proposta e filosofia.

Nesse sentido, o CP pode ter uma percepção por meio desses resultados sobre os processos educativos da escola. São diferentes visões sob um mesmo teto, o que torna importante o compartilhamento dos entendimentos de aspectos como avaliação e planejamento, em momentos onde a presença do coordenador pedagógico é fundante: as reuniões pedagógicas. Por meio das múltiplas opiniões, interpretações a partir dos documentos escolares e das ações praticadas no cotidiano é possível ao CP avaliar, refletir e direcionar sua prática de modo a conduzir o grupo para uma via de entendimento comum. Não se trata de silenciar opiniões diversas, mas de acolher e construir posicionamentos que sigam ao encontro 
do currículo pensado àquela escola.

\section{Categoria 2: Articulação entre o planejamento, avaliação e a atuação docente}

Quando questionadas sobre de que forma o planejamento e a avaliação estão inseridos nos seus fazeres docentes, verificam-se apontamentos quanto à periodicidade, como descrito pela participante A: "estão inseridos de forma diária e contínua, uma vez que estamos sempre planejando e reformulando atividades e acompanhando os alunos". Também surgem declarações relacionadas à forma como é feita essa articulação, conforme depoimento da participante $\mathrm{C}$, quando afirma que o planejamento se insere "de forma reflexiva, diagnóstica e investigativa, visando contextualizar o meio onde está inserida a comunidade escolar".

As falas das participantes se complementam em suas construções a respeito de como é feita essa articulação de suas práticas cotidianas. Conforme Campos (2010), o planejamento e a avaliação são elaborados no cotidiano, sendo o planejamento aplicado com plasticidade, adaptando-se às inúmeras situações que podem ocorrer em sala de aula. Um planejamento não pode ser pensado de forma descolada da temporalidade e contexto de aplicação, sendo aproveitado em anos ou situações subsequentes, pois isso conduz a uma fixidez incompatível com uma educação de qualidade. Boas práticas podem ser repensadas, aprimorando os aspectos positivos, que não necessariamente se repetirão em outras turmas/escolas/anos.

Quanto aos instrumentos que as participantes utilizam em seu planejamento e avaliação, constatam-se três formas distintas de organização dos trabalhos:

Professora A: No planejamento utilizo internet, livros didáticos, revistas. Nas avaliações utilizo trabalhos em grupo, trabalhos individuais, atividades em sala de aula e observação dos alunos.

Professora B: Para planejar eu faço uma sondagem prévia do nível de apreensão dos alunos em relação a determinado conteúdo, faço uma planilha com o que desejo que aprendam, objetivo, recursos (os recursos muitas vezes nem chego a escrever) e sondo os interesses e necessidades de cada turma. Minha avaliação se dá através da observação diária das respostas e envolvimento dos alunos com as atividades propostas e ao final de cada trimestre, avalio-os também através de portfólio contendo todos os trabalhos práticos realizados naquele prazo de tempo.

Professora C: Observação direta, contínua e sistemática.

Observam-se nas três participantes da pesquisa diferentes formas de compreensão dos

Periódico Horizontes - USF - Itatiba, SP - Brasil - e019048 
instrumentos: recursos utilizados na sua construção; forma de registro empregada e modelo sistemático de registro dos instrumentos de avaliação. As diferentes fontes utilizadas na pesquisa educacional, assim como a elucidação para obtenção de novas informações e construção de ideias devem fazer parte da rotina de todo docente, visto que a atualização é necessária para que se caminhe em consonância com as novidades e assuntos trazidos pelos alunos.

Já a participante $C$ apresenta ideias um pouco difusas sobre como deve ser realizada a avaliação e planejamento, dificultando a compreensão do significado dessas tarefas para essa professora. Em contrapartida, a professora B apresenta uma forma sistematizada de construção do panorama de avaliação de seus estudantes, explicitando seu plano de ensino, metodologias, objetivos, recursos e avaliação.

Por fim, quando questionadas sobre como empregam os dados das avaliações que aplicam com seus alunos para reorientar suas práticas, as três participantes responderam de forma positiva. De modo geral, elas utilizam os dados das avaliações para reorientar suas práticas, caso se faça necessário, buscando metodologias diferentes das apresentadas anteriormente, visando à compreensão daquilo que ainda não foi atingido. Também utilizam as avaliações para verificar a necessidade/possibilidade de aprofundar determinado conteúdo, ou não. Nesse sentido, a avaliação adquire um caráter diagnóstico, podendo encaminhar para uma retomada dos conteúdos, se necessário, e, portanto, não construindo um ponto definitivo de chegada, já que se trata de um processo dinâmico (GRILLO; LIMA, 2010).

É possível relacionar as práticas declaradas por essas professoras com a ação da $\mathrm{CP}$, visto que é papel desse profissional o acompanhamento do docente em seu trabalho diário na sala de aula. Discutir planejamento e avaliação por meio dos registros realizados pelo docente, oferece ao $\mathrm{CP}$ a possibilidade de organizar, também com relação ao professor, um planejamento e uma avaliação, oferecendo momentos formativos, que possam dar subsídios às dificuldades desse professor, bem como valorizar suas boas práticas, compartilhando-as com o corpo docente.

\section{Considerações finais}

Foi possível perceber nas três participantes o olhar para avaliação não apenas como instrumento de aferir resultados, mas como forma de se auto avaliarem, serem pesquisadoras de si mesmos, no sentido de pesquisar suas próprias práticas.

Periódico Horizontes - USF - Itatiba, SP - Brasil - e019048 
As respostas obtidas na pergunta relacionada às dificuldades do planejamento e avaliação na escola de atuação dessas participantes não foram analisadas devidos a essas respostas não estarem diretamente relacionadas ao objetivo proposto neste trabalho. Apesar disso, de forma a contribuir para a construção da realidade dessas participantes, tais discursos serviram complementarmente às respostas outras advindas no instrumento de coleta de dados, para a consecução do processo analítico.

Evidenciou-se a importância atribuída por essas participantes ao planejamento e avaliação, bem como constatou-se divergências nas suas compreensões sobre seus significados e aplicações. No contexto individual, estes múltiplos entendimentos não interferem uns nos outros, porém, quando se pensa no coletivo, podem-se antever dificuldades no trabalho do CP na proposição de algum projeto. Saber trabalhar com diferentes concepções faz parte do cotidiano do $\mathrm{CP}$, porém, pensa-se que na tentativa de um trabalho coletivo na escola, por vezes, é necessário o alinhamento destas ideias, expondo-as, buscando pontos que possam ser elucidados a fim de avançar em uma direção comum.

Com relação ao foco deste trabalho - planejamento e avaliação - constatou-se que o ensino e a aprendizagem são indissociáveis, e a avaliação é parte destes processos. Pensa-se que o planejamento e a avaliação sejam elementos tramados no tecido educacional, não havendo como separar os seus fios. O CP, portanto, pode atuar como facilitador no entendimento desta trama, não apenas como agente supervisor do cumprimento das avaliações, mas fazendo com que o professor perceba a riqueza que estes dados podem representar no redirecionamento de suas práticas, qualificando-as e buscando novos caminhos para os fazeres pedagógicos.

\section{Referências}

BATISTA, S. H. S. S. Coordenar, discutir, formar: discutindo conjugações possíveis. In: ALMEIDA, L. R.; PLACCO, V. M. N.S. (Org.) O coordenador pedagógico e o espaço da mudança. 5. ed. São Paulo: Edições Loyola, 2006, p.109-118.

CAMPOS, M. B. Os desafios do planejamento e da prática de avaliação em ambientes on-line. In: GRILLO, M. C.; GESSINGER, R. M.; FREITAS, A. L. S. (Org.) Por que falar ainda em avaliação? Porto Alegre: EDIPUCRS, 2010, p.51-62.

GANDIN, D. Planejamento como prática educativa. São Paulo: Edições Loyola, 1991.

$$
\text { Periódico Horizontes - USF - Itatiba, SP - Brasil - e019048 }
$$


GRILLO, M. C.; LIMA, V. M. R. Dimensões conceituais e operacionais da avaliação. In: GRILLO, M. C. et al (Orgs.). A gestão da aula universitária na PUCRS. Porto Alegre: EDIPUCRS, 2008, p.67-82.

GRILLO, M. C.; LIMA, V. M. R. Especificidades da avaliação que convém conhecer. In: GRILLO, M. C.; GESSINGER, R. M. (Orgs.). Por que falar ainda em avaliação? Porto Alegre: EDIPUCRS, 2010. p.15-22.

FUSARI, J. C. O papel do planejamento na formação do educador. São Paulo: SE/CENP, 1989.

FUSARI, J. C. O planejamento de trabalho pedagógico: algumas indagações e tentativas de respostas. Série Ideias, n.8. São Paulo: FDE/Grupo de Estudo de SP, 1990.

GATTI, B. O professor e a avaliação em sala de aula. Estudos em Avaliação Educacional, 27, p.97-114, 2003.

MIZIARA, L. A. S.; RIBEIRO, R.; BEZERRA, G. F. O que revelam as pesquisas sobre a atuação do coordenador pedagógico. Revista Brasileira de Estudos Pedagógicos, v.95, n.241, p.609-635, 2014.

MORAES, R.; GALIAZZI, M. C. Análise textual discursiva. 2 ed. Ijuí: Editora Unijuí, 2013.

TARDIF, M. Saberes docentes e formação profissional. Trad. Francisco Pereira. 17. ed. Petrópolis: Vozes, 2014.

Recebido em julho de 2018.

Aceito em maio de 2019. 